\title{
A CONCEPTUAL FRAMEWORK FOR SUSTAINABLE EHEALTH IMPLEMENTATION IN RESOURCE- CONSTRAINED SETTINGS
}

\author{
G.B. Fanta ${ }^{1 *} \&$ L. Pretorius ${ }^{1}$
}

\section{ARTICLE INFO}

\section{Article details \\ Presented at the $29^{\text {th }}$ annual conference of the Southern African Institute for Industrial Engineering (SAIIE), held from 24-26 October 2018 in Stellenbosch, South Africa \\ Available online

Contact details

Corresponding author

getnet.fanta@up.ac.za

Author affiliations

1 Department of Engineering and

Technology Management,

University of Pretoria, South Africa

\section{DOI}

http://dx.doi.org/10.7166/29-3-2055
ABSTRACT

There is evidence that several eHealth pilot projects in developing countries could not progress to full-scale implementation sometimes referred to as the 'pilotitis' of the eHealth system. The sustainable eHealth implementation frameworks reported in the literature are linearly modelled, and fail to reflect the nonlinear and dynamic complexity of eHealth systems implementation. This study proposes a sustainable eHealth implementation framework to support the long-term sustainability of eHealth systems in developing countries. The framework addresses the nonlinear and dynamic relationships among elements of the ecosystem in the implementation of eHealth through feedback systems by following a system dynamics method. A literature review and systems approach is used to understand the interactions between the elements of a sustainable eHealth system. System dynamics modelling is applied to develop a nonlinear and dynamic model of sustainable eHealth implementation. The study indicates that the long-term sustainability of eHealth depends not only on technological factors, but also on economic, social, and organisational factors. Moreover, the causal loop diagram highlights the dynamic interplay between the factors of a sustainable eHealth system through feedback loops.

\section{OPSOMMING}

Daar is bewyse dat verskeie elektroniese-gesondheid (e-gesondheid) proefprojekte in ontwikkelende lande nie kon vorder tot volskaalse implementering nie. Die volhoubare implementering van egesondheid raamwerke wat in die literatuur rapporteer word, is lineêr gemodelleer en reflekteer nie die ware nie-lineariteit en dinamiese kompleksiteit wat hiermee assosieer word nie. Hierdie studie stel ' $n$ volhoubare e-gesondheid implementeringsraamwerk voor om die langtermyn volhoubaarheid van e-gesondheidstelsels in ontwikkellende lande te ondersteun. Die raamwerk adresseer die nie-lineêre en dinamiese verhoudings tussen elemente van die ekosisteem in die implementering van e-gesondheid deur terugvoer stelsels deur ' $n$ stelseldinamika benadering te volg. ' $n$ Literatuurstudie en ' $n$ stelselsbenadering is gebruik om die interaksies tussen die elemente van 'n volhoubare e-gesondheidstelsel te verstaan. Die resultate toon dat die langtermyn volhoubaarheid nie net van tegnologiese faktore afhang nie, maar dat ekonomiese, maatskaplike en organisatoriese faktore ook 'n rol speel. Die oorsaaklike-lus diagram beklemtoon die dinamiese wisselwerking tussen die faktore van 'n volhoubare egesondheidstelsel. 
Growth in the use of electronic systems to support healthcare services delivery can be seen in the increasing number of electronic health (eHealth) systems in developing countries [1]. Government and other stakeholders in the developing world are showing a strong desire to use information and communications technology (ICT) in the health sector to replicate the successful revolution of ICT systems in the financial and other sectors [2]. eHealth is defined as the use of ICT for health [3]. The successful implementation of eHealth technologies is believed to improve access, safety, quality, and performance of healthcare services delivery by improving healthcare data management, minimising costs, and reducing medical errors [4,5]. eHealth technology can bridge the healthcare services delivery gap in developing countries, such as the burden of disease, scarcity of healthcare professionals, inequity of healthcare services delivery, and shortage of healthcare budget [3]. The implementation of an infectious disease reporting information management system (IDRIMS) in China improved disease outbreak detection from $30 \%$ to $90 \%$ by 2011 [6]. Despite the highly anticipated benefits of eHealth technologies to strengthen healthcare services delivery, the success of eHealth implementation is low in developing countries [7]. Some of the eHealth implementation challenges are associated with high technology acquisition costs and ongoing maintenance costs $[8,9]$, lack of computer skills by end-users [7], trust and privacy concerns [11], poor ICT infrastructure [12,13], and lack of leadership and political support $[8,12]$. Moreover, in the change management process, organisational, interoperability, psychological, social, legal, and ethical factors can be a barrier to the sustainable implementation of eHealth in developing countries $[6,8,12,13]$.

The success of eHealth implementation depends on the stakeholders' objectives and needs [14]. Moreover, the determinants of success may vary over time as ICT advances [15]. The successful implementation of eHealth is linked to the acceptance of technology by end-users [17], [19]; the long-term sustainability of technology [18]; and managing stakeholders' expectations [19]. eHealth success factors are categorised into technological, organisational, financial, ethical, political, and training groups [20]. The relevance and user-friendliness of a technology, the availability of funds, user involvement, executive support, and ICT infrastructure are some of the success factors that determine the long-term sustainability of eHealth [19].

The next section discusses the 'pilotitis' of eHealth and key factors in the implementation of longterm sustainable eHealth in resource-constrained settings, based on sustainability theory. In this exploratory research, a literature review and a systems approach are used to understand the interactions between the elements of a sustainable eHealth system and to develop a conceptual framework for sustainable eHealth implementation. A system dynamics modelling approach is used to develop a causal loop diagram (CLD) of sustainable eHealth factors to capture the nonlinear interplay among the framework variables. The design science research approach used in this study aims at analysing the interface between eHealth technology and the elements of the operating environment. This research study focuses on proposing a solution to go beyond the 'pilotitis' of eHealth implementation in resource-constrained environments.

\section{LITERATURE}

eHealth implementation efforts in developing countries are fragmented because of pressure from donors and economic and political factors [23]. Most donor-funded electronic health systems are modelled on disease categories such as TB, HIV/AIDS, and malaria according to the information needs of donors $[23,24]$. As a result, multiple information systems run within a healthcare facility without talking to each other electronically. This places the data collection burden on healthcare workers, and causes a dichotomy between the healthcare data team and health systems managers [24]. Besides, several eHealth projects do not scale-up successfully in resource-constrained environments.

\section{1 'Pilotitis' of eHealth}

Scaling-up successful pilot eHealth projects and ensuring the sustainable use of eHealth technologies remains a challenge in the effort to implement successful eHealth systems in resource-constrained settings. The term 'pilotitis' refers to the inability of eHealth projects to break out of the pilot stage [25]. 'Pilotitis' is frequently used by donors and governments to express dissatisfaction with the failure to take the implementation of eHealth projects beyond the pilot stage in low- and middle- 
income countries (LMICs) $[25,26]$. The pilot phase of eHealth projects mainly focuses on the technical feasibility of a system, but it fails to consider other success elements such as organisational and social factors. A successful pilot project may not show similar results in another context because of technological, economic, institutional, and political barriers [26]. As a result, successful pilot eHealth projects seldom scale up in LMICs. There is a great need to integrate isolated pilot eHealth projects across contexts and to ensure their sustainable rollout, especially in LMICs [26]. FranzVasdeki et al. [26] indicated five key components that need to be considered for an effective scaleup of eHealth pilot projects:

- improved evidence,

- technological integration and interoperability,

- $\quad$ sustainable financing,

- $\quad$ global and national policies that support the use of technology, and

- $\quad$ a health community that can design and deploy technologies for health.

\subsection{Scale-up of eHealth}

mTrac is an eHealth system in Uganda that is reported to have scaled-up successfully at the national level. mTrac is a mobile health (mHealth) project that was recognised by the African Development Bank as one of the top ten eHealth projects in 2013 [26]. The system helps to collect, verify, and analyse health-related information from the community and health facilities [26]. mTrac demonstrated success in terms of government ownership and effective scale-up for health information management [26]. mTrac was designed to be interoperable with the existing electronic system (DHIS2) and paper systems (reporting format) [6, 26]. Although infrastructure issues such as limited internet connectivity and the frequent failure of electrical power were challenges in the implementation of mTrac, the availability of good technical support was its strength [6].

It has been indicated that the success of an electronic system depends on the strength of the health system [26]. mTrac's scale-up was achieved because of the focus on the following areas from the beginning of the project [26]:

- the system design addresses interoperability factors,

- the technology is aligned to existing national structure, policies, and institutions,

- $\quad$ the coordination of multiple stakeholders and leveraging of resources, and

- $\quad$ minimising government investment to ensure sustainability.

In China, IDRIMS is another eHealth project to scale-up successfully. The system is used by over 68,000 facilities to report and track disease outbreaks. The system has improved outbreak detection significantly [6]. Besides, the incentives offered to report disease outbreaks have significantly improved the data quality of IDRIMS [6]. The capacity and willingness of the end-users to accept the technology influences the quality of the data. Therefore, training and supervision of the end-users is important in building the basic skills that are required to provide data and to use the system [6]. Data use to improve health outcomes increases the quality of the data [6]; But if the data has little relevance to the activities of data-collecting facilities, there will be only limited interest from facility users and management to maintain the data quality at a high level and to integrate the system with existing eHealth systems [6].

The implementation of sustainable eHealth requires a digital health intervention to move beyond 'pilotitis' [6]. The ability of the new system to integrate with the existing process and technologies is another important factor in the implementation of eHealth [6]. Data quality is crucial in the longterm sustainability and scaling-up of eHealth systems. Creating awareness of the relevance of the system to the data-collecting facilities and to end-users through training will have an impact on the quality of the data [6].

\subsection{The theory of sustainable eHealth}

The discussion of sustainability is usually associated with ecological efficiency, and focuses on economic, social, and environmental pillars [27]. Sustainability aims simultaneously to achieve the economic success, social benefits, and environmental quality of a system. The three pillars of sustainability are used to assess the sustainability of the dairy industry [28], of system design [27], and of financial institutions' lending policy [29]. Other definitions link sustainability to the continued 
operation of a particular system of interest within its environment $[27,30]$. The long-term sustainability of eHealth technology is associated with the fit between the technological, economic, social, and organisational factors $[30,31]$.

Technology is always embedded in the sub-systems of the economy, society (and its institutions), and the natural environment [31]. In the case of eHealth implementation, the natural environment is the healthcare institution where the technology is deployed. In this study, the boundary is scaled down from planet Earth to the organisational level. Thus the boundary of the eHealth implementation environment is set around the healthcare organisation where the technology is implemented. Similarly, instead of representing the entire population on planet Earth in this study, 'society' refers to employees within the organisation who are either users of eHealth or consumers of the information product of the system. The success of eHealth technology is also influenced by the economic affordability of the healthcare institution. So the economic and social factors are a sub-system of the healthcare institution.

The society (patients and caregivers) and economy (finance) depend on the environment (healthcare organisation) that provides all the resources for the successful implementation of the technology [31]. Figure 1 depicts the key factors of sustainable technology development and the possible interaction of the technology with the three pillars of sustainability. The implementation of sustainable eHealth technology may bring economic benefits to patients, caregivers, and healthcare organisation. The benefits to patients and caregivers include decreased expense, a reduced workload, and the elimination of redundant laboratory and radiology tests [5]. The healthcare organisation bears two-thirds of the overall costs of eHealth intervention; so the financial gain to the organisation contributes to the sustainability of the technology [32]. The technology may streamline the service delivery process and reduce the problems of missing patient medical files, medical errors, and patient waiting times to improve the branding of the organisation and attract patients [5]. The healthcare organisation may minimise the legal fines associated with missing patient medical files and medical errors by implementing eHealth systems.

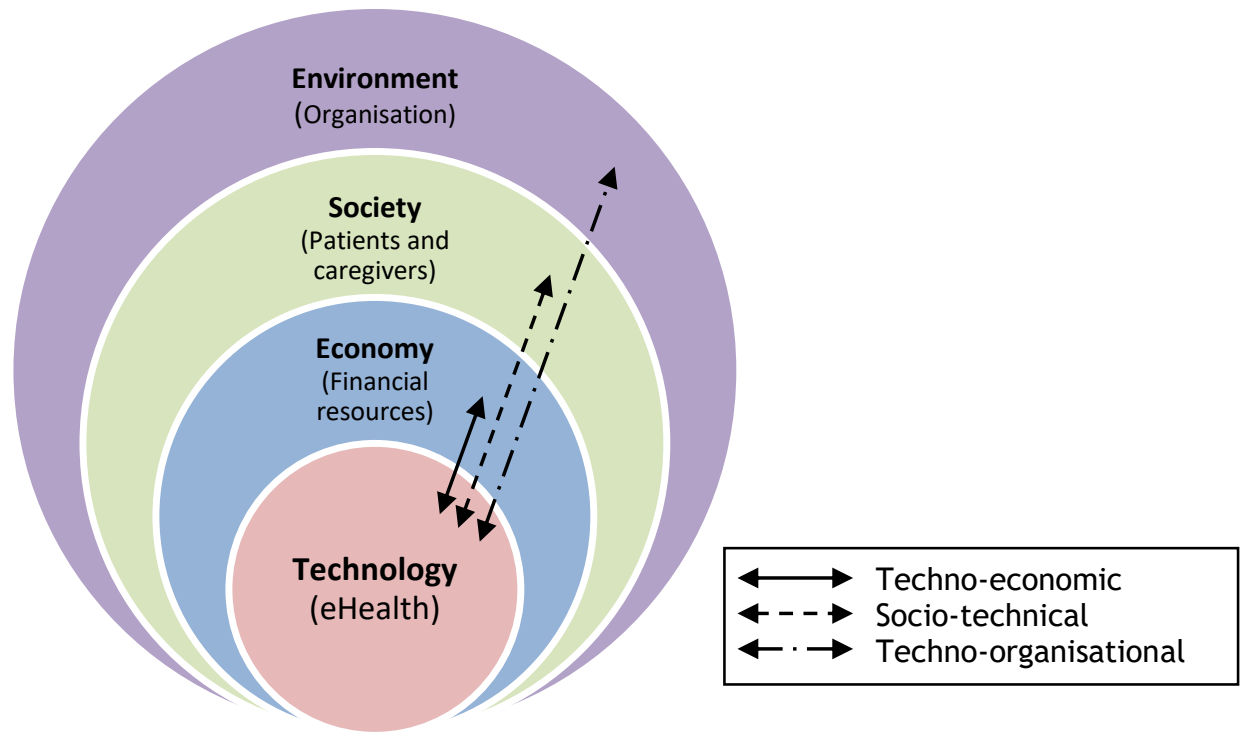

Figure 1: Development of sustainable technology [31]

The technological capability of eHealth systems is one of the key factors that influence the successful implementation of a technology. The functional and non-functional requirements, interoperability, and user interface designs are some of the key success factors of eHealth implementation in the technology category [33]. The long-term sustainability of eHealth technology depends on the economic, social, and organisational sustainability in which the technology is embedded. 


\subsubsection{Economic sustainability of eHealth technology}

Economic factors are one of the key factors in the long-term sustainability of eHealth implementation [34]. Research studies report the economic attractiveness of eHealth interventions to wider groups of stakeholders [35]. Yet there have been few economic evaluation research studies in developing countries [35]. In developing countries, where there is a scarcity of resources, the economic factor plays a significant role in the long-term sustainability of eHealth. Short-term grants from donor agencies to developing countries need to consider not only the initial investment, but also ongoing maintenance costs to sustain the eHealth system [34]. Costs associated with the initial investment, change management, human resources, training, and maintenance are direct costs of an eHealth intervention [32].

\subsubsection{Social sustainability of eHealth technology}

'Social subsystem' refers to the relationship between people within and across organisations [36]. The eHealth system can show long-term sustainability if the end-users within the organisation accept the technology. The individuals' feelings about the usefulness of the system, their motivation, the user's problem-solving skills, competence, and confidence to use the system are factors that have a direct influence on the process and performance of an eHealth system [24]. The end-users' skill in using electronic systems is lower in developing countries than in developed countries. So sustainable eHealth needs to consider the end-users' attitudes to accepting the technology to ensure social sustainability.

\subsubsection{Organisational sustainability of eHealth technology}

It is not logical to exclude organisational sustainability in the process of sustainable eHealth implementation, because an eHealth system is implemented and used within an organisation. The organisational sustainability of eHealth is influenced by factors such as organisational structure, procedures, culture, rules, values and practices, resources, management support, supervision, and leadership. Organisational determinants affect the success of eHealth technologies directly or indirectly [24]. The shortage of resources, poor ICT infrastructure, and an unreliable electricity supply deter the long-term sustainability of eHealth systems in developing countries.

In summary, the technological, social, organisational, and economic factors of eHealth implementation are well-covered in many separate research studies. However, the complexity that arises from the interplay among the technological factor with social, organisational, and economic factors of eHealth implementation in healthcare settings requires further research. The nonlinear nature of eHealth implementation can be understood through the study of the socio-technical, techno-organisational, and techno-economic factors of eHealth implementation.

\subsection{The interplay between sustainability factors of eHealth technology}

The techno-economic, socio-technical, and techno-organisational factors evolve from the dynamic interplay between the system of interest (technology) and the three pillars of sustainability (Figure 1). The nonlinear nature of eHealth implementation can be understood through the study of technological interaction with the social, organisational, and economic elements of healthcare institutions. Therefore, the three concepts - socio-technical, techno-organisational, and technoeconomic - are discussed below.

\subsubsection{Techno-economic factors}

The successful implementation of eHealth technology depends on financial factors such as the initial investment and on-going maintenance costs. The implementation of eHealth in developing countries is donor-driven; and that usually focuses on the pilot phase of the implementation [13]. Limited financial resources within Ministries of Health, and the short project span of donor agencies, hinder the scale-up and sustainability of eHealth projects in developing countries [12]. The techno-economic aspect emerges from the interplay between the technology and economic factors, and plays a significant role in the long-term sustainability of eHealth systems in resource-constrained environments.

\subsubsection{Socio-technical factors}

The term 'socio-technical system' originally emerged to describe systems that involve complex interactions between people through technology to create a community [36]. Harrison et al. [37] indicate that a socio-technical system addresses dynamic and mutual influences among the social subsystems (people, tasks, and relationships), technical subsystems (technologies, techniques, task performance methods, and work settings) in organisational environments. The term 'socio-technical 
system; is widely used to describe many complex systems; hence the interaction among people, technologies, and context need to be considered during the development process [36]. Sociotechnical factors influence the behaviour of users in accepting eHealth, and determine its sustainability.

\subsubsection{Techno-organisational factors}

Techno-organisational factors deal with the dynamic interactions between the technological and organisational elements of sustainable eHealth implementation. Most businesses operate mainly in a complex domain that requires an understanding of the context of the operating environment and the nonlinear dynamic interaction among organisational elements [38]. The techno-organisational factors of sustainable eHealth implementation deal with subjects of user training to increase competency [36]; change management to ensure user-oriented processes [37]; data management to improve data quality [21]; stakeholders' engagement to increase technology acceptance [36,37]; project management to balance schedule, quality, and budget effectively [38]; and organisational communications for the effective exchange of timely and accurate information [38].

\subsection{The complexity of eHealth systems}

Healthcare service delivery is complex, as it involves the coordination and management of large numbers of highly specialised and distributed personnel, multiple streams of information, and material and financial resources across multiple care settings [2,37]. One of the complexities of a healthcare system is associated with large problem spaces, which address about 500,000 illnesses [40]. The social system of healthcare is composed of many people who must work together to deliver healthcare services. It includes healthcare providers, patients, and their families [40]. Complexity emerges from unpredictable patterns as elements of a system interact with each other; it is characterised by a nonlinear cause-and-effect relationship [38]. According to Snowden \& Boone [38], a complex system is characterised by the following:

- A large number of nonlinear interacting elements.

- Minor changes can trigger major consequences.

- The system is dynamic, and exhibits emerging characteristics.

- The elements of the system evolve with one another and with the environment.

- The external conditions and systems change constantly, so are difficult to predict.

- $\quad$ The agents and the system constrain one another; so one cannot predict or forecast the future.

The unpredictability and intellectual nature of humans creates complexity and makes a human modelling process very difficult [38]. "Humans have multiple identities and can fluidly switch between them without conscious thought" [38]. Moreover, humans make decisions based on the experience of past failure and success, rather than on logical and definable rules [38]. These distinctive characteristics make organisational systems involving humans complex. Sterman [39] note that dynamic complexity arises because systems are dynamic, tightly coupled, nonlinear, history-dependent, self-organising, adaptive, counter-intuitive, policy-resistance, and characterised by trade-offs. Thus the implementation of eHealth technology falls in the complex domain.

Although research studies recognise the complexity of healthcare organisations, eHealth implementation frameworks fail to address the dynamic and nonlinear nature of the problem [41]. The nonlinear relationship of eHealth implementation with complex healthcare settings requires appropriate techniques that can handle the dynamic complexity of systems [39]. The complexity of the interconnected components of health systems, and the various stakeholders' interest in the implementation of eHealth, can be addressed with methods such as network analysis, agent-based modelling, system thinking, system engineering, and system dynamics modelling. A system dynamics model is powerful in dealing with the interation of complex systems through feedback loops. Thus the system dynamics modelling and simulation approach applied in this study is an appropriate method for understanding the behaviour of complex systems [39].

\subsection{System dynamics method}

A system dynamics method is a computer modelling and simulation approach to understanding the behaviour of complex and nonlinear systems. The models and techniques developed through elicitation and mapping processes are an initial hypothesis about the structure of a system that must be tested [39]. The mental models are dynamically deficient, omit feedbacks, and have time delays, 
accumulations, and nonlinearities [39]. Simulation is a cost-effective practical way to test the models [39]. Simulation speeds up and strengthens the learning feedback by correcting discrepancies between the formal and mental models, as well as assumptions such as model boundaries, time horizons, and dynamic hypotheses [39].

Causal loop diagrams (CLDs) are used to represent the feedback structure of systems [39]. CLDs are important tools for capturing hypotheses about the causes of dynamics; for eliciting and capturing the mental models of individuals or teams, and for communicating feedback responsible for a problem [39]. The causal influence between variables is denoted by variables connected by arrows, representing causal links [39]. The polarities - either positive $(+)$ or negative $(-)$ - assigned to each causal link indicate the change in the dependent variable when the independent variable changes. A positive link indicates that an increase in cause increases a dependent variable. Similarly, if the cause decreases, the effect decreases below what it would otherwise have been [39]. On the other hand, a negative link shows that an increase in the cause makes the effect decrease; and a decrease in the cause will result in an increase of the dependent variable above what it would otherwise have been [39]. A loop identifier highlights positive feedback loops (reinforcing loops) or negative feedback loops (balancing loops) [39].

\section{A CONCEPTUAL FRAMEWORK FOR SUSTAINABLE EHEALTH IMPLEMENTATION}

The conceptual framework for sustainable eHealth implementation is developed in this paper with the focus on technology acceptance and the use of information for decision-making. The framework addresses the influence of end-users in ensuring sustainable eHealth projects. A sustainable eHealth system should address the needs of the majority of the stakeholders to be accepted by its end-users. The political and social factors associated with the perceptions, attitudes, and needs of stakeholders should be recognised in the implementation of a successful eHealth system [6]. An eHealth system should be used or accepted by the end-users to demonstrate its sustainability. Besides, the information generated from the system has to be used for decision-making, and the system should scale-up beyond the pilot phase to prove long-term sustainability.

Cresswell and Sheikh [41] indicate that technological, social, and organisational considerations influence the usefulness and usability of technological innovations. Based on sustainability theory and on reviews of the eHealth literature, four major factors -social, economic, environmental (organisational), and technological - are identified as key elements of sustainable eHealth implementation. The conceptual framework for the sustainability of eHealth aims to realise the fit among the social, economic, environmental, and technological factors (Figure 1).

The technological, social, organisational, and economic factors of eHealth implementation are wellcovered in many research studies, but are usually modelled linearly. However, this study recognises the nonlinearity of eHealth implementation, and the influence of feedback loops that emerge from the interplay between the technological, social, organisational, and economic elements. A systems approach encourages an understanding of the holistic view of a system instead of focusing only on specific elements. The sustainable implementation of an eHealth system in a healthcare setting is a complex problem that requires a systems approach to handle the complexity. A systems approach is an appropriate method for understanding a system holistically instead of thinking about elements in isolation. Figure 2 describes the factors of sustainable eHealth implementation and their nonlinear interactions. The conceptual framework for sustainable eHealth implementation adapts the traditional linear input-process-output-outcome-and-impact approach of sustainable programme implementation, and incorporates sustainability pillars and feedback loops to enhance an understanding of the nonlinear dynamics of eHealth system implementation behaviour.

\subsection{Inputs dimension}

\subsubsection{Technological factors}

The technological factors focus on the technical capability of the eHealth system to satisfy the need of its key stakeholders. The user-friendliness, flexibility, reliability, availability, accuracy, efficiency, data quality, scalability, and adaptability of the eHealth system are addressed by the technological factors [42,43]. The acceptance of technology is influenced by the elements of the technological factors that are subcategorised into three quality groups: system quality, information quality, and service quality [44]. The information systems (IS) success model presents the three 
quality factors as key to measuring the technological quality of electronic systems $[45,46]$. The technological factors addressed in the framework are discussed in Table 1.

System quality is linked to ease of use, functionality, reliability, flexibility, portability, integration, and importance of the information technology [46].

Information quality refers to accuracy, timeline, completeness, relevance, and consistency of the information stored in the eHealth database [45].

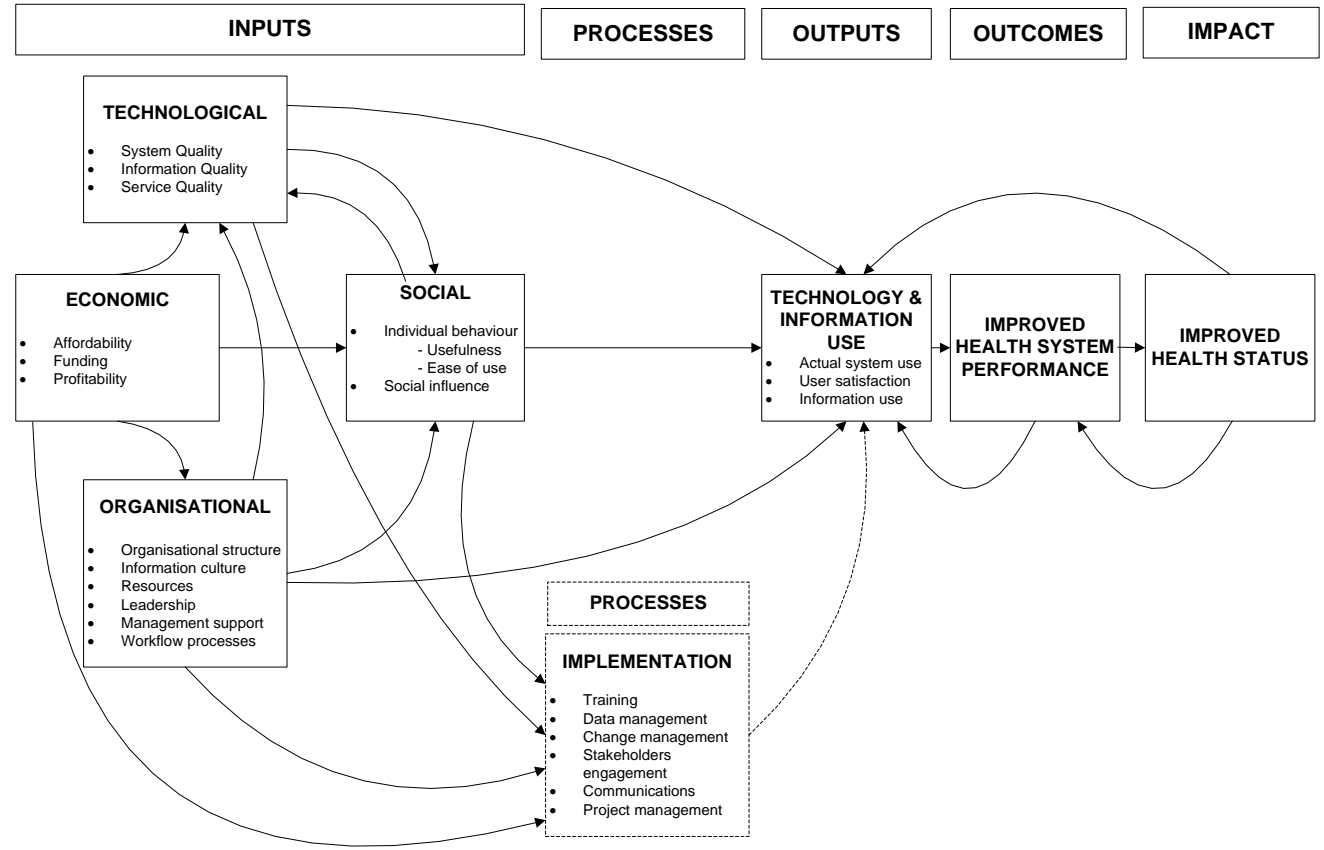

Figure 2: A conceptual framework for sustainable eHealth implementation

Table 1: Technological factors of sustainable eHealth implementation

\begin{tabular}{|l|l|}
\hline Technological factors & Descriptions \\
\hline System quality & The technical soundness or technical success of the technology [45,46]. \\
\hline Information quality & The quality of information system outputs [47]. \\
\hline Service quality & $\begin{array}{l}\text { The level of overall support delivered to end-users to meet their } \\
\text { expectations [47]. }\end{array}$ \\
\hline
\end{tabular}

Service quality represents the reliability, responsiveness, assurance, and empathy of technical support, as well as up-to-date hardware and software to facilitate the use of the information system [46].

\subsubsection{Social factors}

The social sub-system represents the people and cultural factors, the tasks, and the structure of an organisation [36]. In the context of eHealth systems, the social factors represent the ability of eHealth to address stakeholders' related issues such as ethical, behavioural, cultural, and stakeholder needs in the processes of eHealth development, implementation, operation, and improvement [42]. It aims at improving clinical safety, quality of care, equity of healthcare services, decision-making, and speed of service delivery to all stakeholders $[3,43]$.

The social factors take account of individual behaviour - i.e., the individual's perception of a system's usefulness and ease of use [48]. Perceived usefulness and perceived ease of use are the two popular end-user perceptions that influence the successful acceptance of eHealth technologies 
in the social dimension of sustainable eHealth implementation [49]. Table 2 addresses the social factors included in the framework.

Table 2: Social factors of sustainable eHealth implementation

\begin{tabular}{|l|l|}
\hline Social factors & Descriptions \\
\hline Individual perceptions & $\begin{array}{l}\text { The attitude, behaviour, and personal demography of individuals about } \\
\text { using the information system [50]. }\end{array}$ \\
\hline Social factors & $\begin{array}{l}\text { The influence of peer groups or social networks on an individual's } \\
\text { behaviour in using technology [50]. }\end{array}$ \\
\hline
\end{tabular}

Perceived usefulness and perceived ease of use, as indicated, are two important individual perceptions to improve the understanding of user acceptance processes, according to the technology acceptance model (TAM) [48].

- Perceived usefulness is defined as "the degree to which a person believes that using a particular system would enhance his or her job performance" [48].

- Perceived ease of use refers to "the degree to which a person believes that using a particular system would be free of effort" [48].

Support from supervisors and senior management, the influence of co-workers, the prestige of users, and the representation of users in the system decision are social influences in the social dimension of sustainable eHealth systems [49].

\subsubsection{Organisational factors}

The successful implementation of an eHealth system is influenced by the settings of the operating environment and its dynamic interaction with the technology. 'Operating environment' refers to organisational settings that influence the implementation and use of eHealth technology in healthcare facilities [33]. The healthcare team operates in the context of the health institution, which is influenced by the resources and the values and practices of the organisation [24].

The organisational culture, and the material, financial, and human resources available through the organisation play a key role in the successful implementation of eHealth [51]. The environmental factors address issues internal to the organisation - i.e., factors under the organisation's control [24]. The organisational factors included in the framework are indicated in Table 3.

Table 3: Organisational factors of sustainable eHealth implementation

\begin{tabular}{|l|l|}
\hline Organisational factors & Descriptions \\
\hline Organisational structure & $\begin{array}{l}\text { The coordination of different healthcare teams to work together and } \\
\text { achieve the organisational goal [44]. }\end{array}$ \\
\hline Information culture & $\begin{array}{l}\text { The organisational rule, values, and practices of end-users in } \\
\text { information and technology use - i.e., the culture of data collection, } \\
\text { analysis, and use of information for decision-making [24]. }\end{array}$ \\
\hline Resources & $\begin{array}{l}\text { Availability of electric power, ICT infrastructure, financial and human } \\
\text { resources [24]. }\end{array}$ \\
\hline Management support & $\begin{array}{l}\text { The general support level offered by top management, which includes } \\
\text { encouraging the use of a system, allocating resources, understanding } \\
\text { the benefits of the system, and intent to see users happy to use } \\
\text { the system [47]. }\end{array}$ \\
\hline Organisational policy & $\begin{array}{l}\text { The way of ensuring internal and external strategic consistency when } \\
\text { using technology [52]. }\end{array}$ \\
\hline Workflow processes & $\begin{array}{l}\text { The way in which activities and working processes are organised and } \\
\text { executed by users [44]. }\end{array}$ \\
\hline
\end{tabular}

\subsubsection{Economic factors}

Economic factors aim to improve profits and reduce health care expenses [53]. The economic outcomes are directly affected by the affordability of connectivity, such as mobile cellular tariffs, broadband internet tariffs, and eHealth system procurement prices $[43,53]$. The 'economic factors' of eHealth are financial resources such as the availability of sustainable funding, affordability of technology, cost-effectiveness, and return on investment [43,53]. Table 4 shows the economic factors addressed in the framework. 
Table 4: Economic factors of sustainable eHealth implementation

\begin{tabular}{|l|l|}
\hline Economic factors & Descriptions \\
\hline Affordability & $\begin{array}{l}\text { The financial capacity of the healthcare organisation to invest in } \\
\text { eHealth systems [55]. }\end{array}$ \\
\hline Funding & $\begin{array}{l}\text { The availability of sustainable funding to acquire and maintain the } \\
\text { eHealth systems [56]. }\end{array}$ \\
\hline Profitability & $\begin{array}{l}\text { The degree to which the implementation of eHealth systems yields } \\
\text { financial gain [27]. }\end{array}$ \\
\hline Financial incentives & The facilitation of eHealth use through financial rewards [57]. \\
\hline
\end{tabular}

The economic factors play a significant role in the process of sustainable eHealth scale-up, especially in LMICs, where most of the projects are financed by nongovernmental funding bodies and international organisations.

\subsection{Processes dimension}

The processes dimension of the conceptual framework focuses on the eHealth implementation processes. The implementation process facilitates the conversion of input factors to outputs, as indicated in Figure 2. Table 5 shows the implementation process factors that influence the success of an eHealth system.

Table 5: The implementation process factors of sustainable eHealth implementation

\begin{tabular}{|l|l|}
\hline Implementation factors & Descriptions \\
\hline Data management & $\begin{array}{l}\text { The collection, storage, quality control, processing, compilation, } \\
\text { analysis, and presentation of data [23]. }\end{array}$ \\
\hline Project management & $\begin{array}{l}\text { An application of knowledge, skills, tools, and techniques to project } \\
\text { activities in order to fulfil stakeholder needs and to balance schedule, } \\
\text { quality, and budget expectations [58]. }\end{array}$ \\
\hline Stakeholder engagement & $\begin{array}{l}\text { The involvement of key stakeholders in the process of eHealth } \\
\text { implementation, starting from the planning phase to reduce } \\
\text { resistance, increase acceptance, and meet stakeholder needs } \\
\text { [41,59]. }\end{array}$ \\
\hline Communications & $\begin{array}{l}\text { An effective exchange of timely and accurate information with all } \\
\text { relevant stakeholders to improve informed decision-making [58]. }\end{array}$ \\
\hline Change management & $\begin{array}{l}\text { The processes include the identification of the consequences; } \\
\text { prioritisation; recognition of appropriate requirements; creation of } \\
\text { strategic plans; informing about and motivating changes; introduction } \\
\text { of new technologies; and continuous evaluation of their impact [60]. }\end{array}$ \\
\hline Training & $\begin{array}{l}\text { The amount of training provided to the organisation by internal or } \\
\text { external entities [16]. }\end{array}$ \\
\hline
\end{tabular}

\subsection{Outputs dimension}

Actual technology use, the level of users' satisfaction, and the use of information products for decision-making are the expected immediate outputs of eHealth implementation $[24,46,48,49]$. The acceptance of technology by its end-users is the basis for the long-term sustainability of eHealth $[48,49]$. The factors in the outputs dimension that are selected for the framework for sustainable eHealth implementation mainly come from the technology acceptance model (TAM) $[48,49]$ and information system success model (IS success model) [46]. The variables in the outputs dimension are discussed in Table 6.

Table 6: The outputs dimension of sustainable eHealth implementation

\begin{tabular}{|l|l|}
\hline Output factors & Descriptions \\
\hline Actual system use & $\begin{array}{l}\text { The use of eHealth technology, or having first-hand experience of the } \\
\text { technology [61,62]. }\end{array}$ \\
\hline Users' satisfaction & $\begin{array}{l}\text { The use of the eHealth system, recognising its ease of use and the } \\
\text { usefulness of the technology in performing day-to-day tasks. }\end{array}$ \\
\hline Information use & $\begin{array}{l}\text { The use of reports generated by the eHealth system for discussions, } \\
\text { advocacy, decisions, and referrals for action at a higher level [24]. }\end{array}$ \\
\hline
\end{tabular}


Not only the actual system use, but also the satisfaction of users is important to the long-term sustainability of the eHealth system. Dissatisfied users are more likely to provide low-quality data, or to fail to capture critical information that affects the overall quality of the information generated by the eHealth system. Poor data quality affects the accuracy of the decisions made by the information's users. Moreover, dissatisfied users might stop using eHealth at any time, affecting the sustainability of the technology. So the outputs dimension is a necessary condition for the success of eHealth implementations.

\subsection{Outcomes dimensions}

An improved health system performance represents the outcomes dimension of sustainable eHealth implementation [24]. It aims to reduce healthcare costs to achieve the health system's economic outcomes, and to deliver efficient clinical services to ensure patient satisfaction [63]. Table 7 shows some of the key outcomes dimensions that can be achieved through the successful implementation of eHealth systems.

Table 7: The outputs dimension of sustainable eHealth implementation

\begin{tabular}{|l|l|}
\hline Outcome factors & Descriptions \\
\hline Decision-making & $\begin{array}{l}\text { The availability of quality data for research and evidence-based } \\
\text { decision making to improve health care services delivery [64]. }\end{array}$ \\
\hline Supply chain system & $\begin{array}{l}\text { The availability of essential drugs and avoiding stock-outs through an } \\
\text { improved supply chain system [64]. }\end{array}$ \\
\hline Emergency management & $\begin{array}{l}\text { The capacity to control disease outbreaks, and handle accidents and } \\
\text { natural disasters through emergency care services [64]. }\end{array}$ \\
\hline Clinical service & $\begin{array}{l}\text { Reduced waiting times, shorter hospital stays, and quicker healthcare } \\
\text { services delivery to patients [64]. }\end{array}$ \\
\hline Healthcare cost & $\begin{array}{l}\text { Reduced healthcare cost by avoiding costs associated with travel and } \\
\text { redundant laboratory and radiology tests [5]. }\end{array}$ \\
\hline
\end{tabular}

\subsection{Impact dimension}

The impact dimension focuses on achieving an improved health status in reducing morbidity, avoiding preventable mortality, minimising hospitalisation, increasing life expectancy, and achieving a high quality of life through the implementation of eHealth systems [24,63]. An improved health status for everyone is the ultimate objective or the final goal of implementing eHealth systems [24].

Table 8: The impact dimension of sustainable eHealth implementation

\begin{tabular}{|l|l|}
\hline Impact factors & Descriptions \\
\hline Life expectancy & The average time (in years) a person is expected to survive. \\
\hline Morbidity & The state of having a disease or a symptom of a disease. \\
\hline Mortality & The state or condition of being subject to death. \\
\hline Hospitalisation & The state of admission to hospital for treatment. \\
\hline Quality of life & The average period of life without illness. \\
\hline
\end{tabular}

Table 8 shows the impact factors that can be achieved through the implementation of eHealth systems for improved health status. eHealth technology is in the relatively early phase of implementation in developing countries. As a result, measuring its long-term impact is a difficult task. Besides, eHealth is an integral part of a bigger health care system; so an improved health status may be as a result of the optimisation of other healthcare processes.

\section{THE CLD OF SUSTAINABLE EHEALTH IMPLEMENTATION}

The conceptual framework for sustainable eHealth implementation has been converted to a CLD as part of this research to show the feedback structure. Figure 3 represents the CLD for sustainable eHealth implementation. The feedback structure of sustainable eHealth implementation captures the hypotheses about the causes of the dynamics.

The CLD demonstrates the interplay between the technological, economic, social, and organisational factors that influence the sustainability of eHealth systems. The two balancing and seven reinforcing 
loops are used to describe the feedback structure. The balancing loops highlight the negative influence of terminated users on the acceptance of technology and on the information culture in the technology implementing organisation. On the other hand, the reinforcing loops highlight the positive feedback structures that promote the acceptance of technology and users' satisfaction. Table 9 describes the loop names and the elements of the loop structure represented in the CLD (Figure 3). The (+) and (-) symbols before the loop names depict the reinforcing or balancing loops respectively.

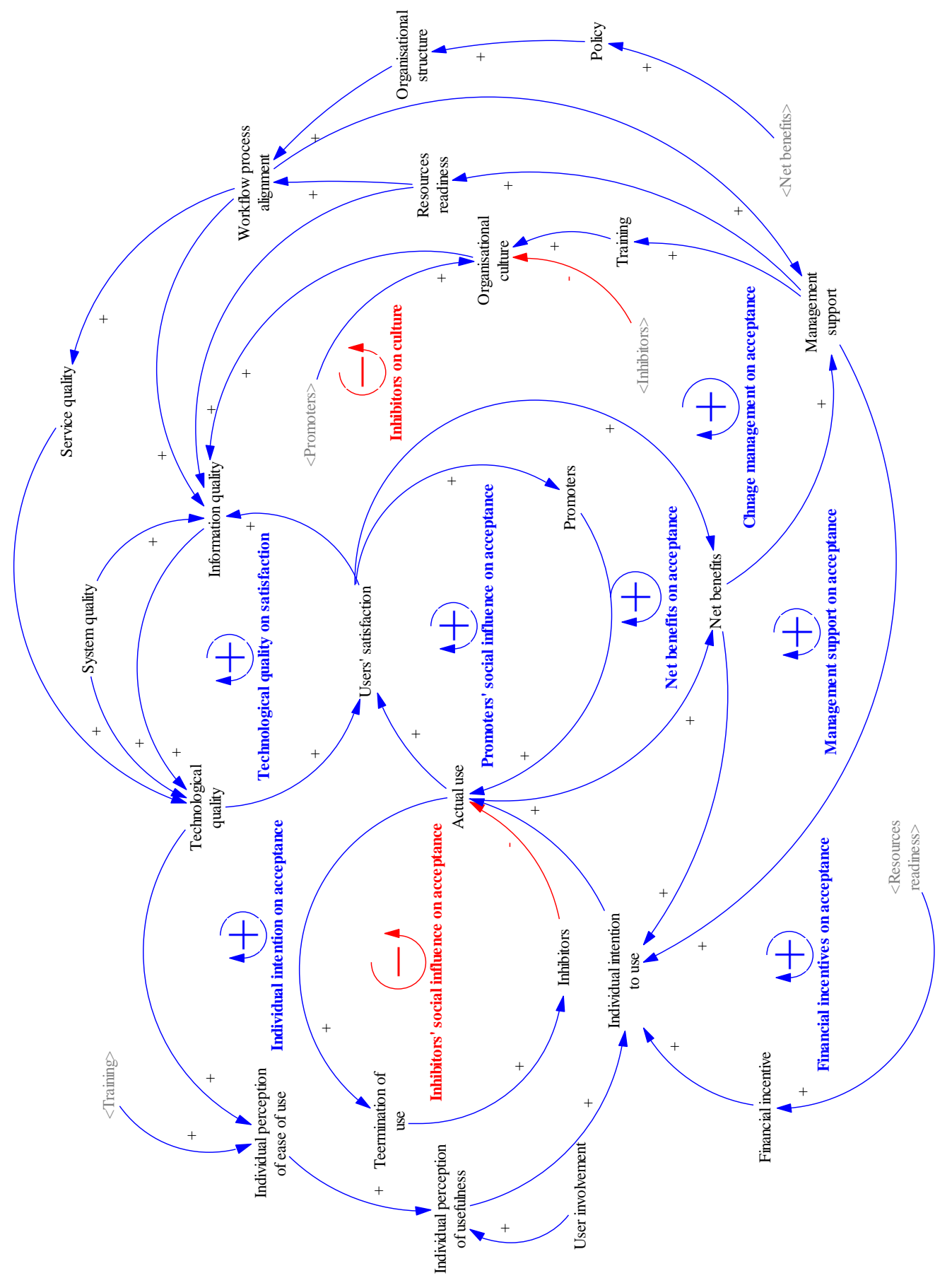

Figure 3: CLD of sustainable eHealth factors 
Table 9: The reinforcing and balancing loops of sustainable eHealth implementation

\begin{tabular}{|c|c|}
\hline Loop names & Descriptions of the loop structure \\
\hline $\begin{array}{l}\text { (+) Individual intention on } \\
\text { acceptance }\end{array}$ & $\begin{array}{l}\text { Individual intention to use } \rightarrow \text { Actual use } \rightarrow \text { Users' satisfaction } \rightarrow \text { Information } \\
\text { quality } \rightarrow \text { Technological quality } \rightarrow \text { Individual perception of ease of use } \rightarrow \\
\text { Individual perception of usefulness } \rightarrow \text { Individual intention to use }\end{array}$ \\
\hline $\begin{array}{l}\text { (+) Promoters' social } \\
\text { influence on acceptance }\end{array}$ & Promoters $\rightarrow$ Actual use $\rightarrow$ Users' satisfaction $\rightarrow$ Promoters \\
\hline $\begin{array}{l}\text { (+) Technological quality on } \\
\text { satisfaction }\end{array}$ & $\begin{array}{l}\text { Technological quality } \rightarrow \text { Users' satisfaction } \rightarrow \text { Information quality } \rightarrow \\
\text { Technological quality }\end{array}$ \\
\hline $\begin{array}{l}\text { (-) Inhibitors' social } \\
\text { influence on acceptance }\end{array}$ & Inhibitors $\rightarrow$ Actual use $\rightarrow$ Termination of use $\rightarrow$ Inhibitors \\
\hline $\begin{array}{l}\text { (+) Financial incentive on } \\
\text { acceptance }\end{array}$ & $\begin{array}{l}\text { Financial incentive } \rightarrow \text { Individual intention to use } \rightarrow \text { Actual use } \rightarrow \text { Users' } \\
\text { satisfaction } \rightarrow \text { Net benefits } \rightarrow \text { Management support } \rightarrow \text { Resources' readiness } \rightarrow \\
\text { Financial incentive }\end{array}$ \\
\hline $\begin{array}{l}\text { (+) Management support on } \\
\text { acceptance }\end{array}$ & $\begin{array}{l}\text { Management support } \rightarrow \text { Resource readiness } \rightarrow \text { Information quality } \rightarrow \\
\text { Technological quality } \rightarrow \text { Individual perception of ease of use } \rightarrow \text { Individual } \\
\text { perception of usefulness } \rightarrow \text { Individual intention to use } \rightarrow \text { Actual use } \rightarrow \text { Users' } \\
\text { satisfaction } \rightarrow \text { Net benefits } \rightarrow \text { Management support }\end{array}$ \\
\hline $\begin{array}{l}\text { (+) Change management on } \\
\text { acceptance }\end{array}$ & $\begin{array}{l}\text { Workflow process alignment } \rightarrow \text { Management support } \rightarrow \text { Training } \rightarrow \text { Organisational } \\
\text { culture } \rightarrow \text { Information quality } \rightarrow \text { Technological quality } \rightarrow \text { Users' satisfaction } \rightarrow \\
\text { Promoters } \rightarrow \text { Actual use } \rightarrow \text { Net benefits } \rightarrow \text { Policy } \rightarrow \text { Organisational structure } \rightarrow \\
\text { Workflow process alignment }\end{array}$ \\
\hline $\begin{array}{l}\text { (+) Net benefits on } \\
\text { acceptance }\end{array}$ & $\begin{array}{l}\text { Net benefits } \rightarrow \text { Intention to use } \rightarrow \text { Actual use } \rightarrow \text { Users' satisfaction } \rightarrow \text { Net } \\
\text { benefits }\end{array}$ \\
\hline (-) Inhibitors on culture & $\begin{array}{l}\text { Inhibitors } \rightarrow \text { Organisational culture } \rightarrow \text { Information quality } \rightarrow \text { Technological } \\
\text { quality } \rightarrow \text { Users' satisfaction } \rightarrow \text { Promoters } \rightarrow \text { Actual use } \rightarrow \text { Termination of use } \rightarrow \\
\text { Inhibitors }\end{array}$ \\
\hline
\end{tabular}

\section{CONCLUSIONS}

The 'pilotitis' of eHealth is a concern in the large-scale and sustainable implementation of eHealth projects; yet others claim that it is an indication of the emerging interest in the field by a group of stakeholders. The long-term sustainability of eHealth is influenced not only by technological factors, but also by the economic, social, and organisational factors of the operating environment. The sustainable eHealth implementation framework addresses the dynamic complexity of eHealth implementation using feedback systems. The framework shows the nonlinear interplay between the factors of sustainable eHealth implementation. A systems approach is applied to understand the holistic structure of a sustainable eHealth ecosystem. Furthermore, a system dynamics method is used to address the nonlinear relationships among the elements of the eHealth system, depicted using a CLD.

The inputs, processes, outputs, outcomes, and impact are adapted from a sustainable project development framework and extended by adding nonlinearity. The operating environment of eHealth technology is grouped under the economic, social, and environmental (organisational) pillars. The CLD is represented by two balancing and seven reinforcing loops to capture the dynamics of sustainable eHealth implementation under the technological, economic, social, and organisational categories. The results of this research are part of a future system dynamics simulations study that will be extended to develop a stock and flow diagram. Eventually, the developed system dynamics model will support the effort of sustainable eHealth implementation in resource-constrained settings.

\section{REFERENCES}

[1] Cargo, M. 2013. South Africa mHealth landscape. Johannesburg: GSMA. Retrieved from https://www.gsma.com/mea/wp-content/uploads/2014/09/South-Africa-mHealth-Landscape_June2013-1.pdf.

[2] Reid, P.P., Compton, W.D., Grossman, J.H. \& Fanjiang, G. 2005. Building a better delivery system: A new engineering/health care partnership. Washington. Retrieved from http: / /www.nap.edu/catalog/11378.html.

[3] WHO. 2011. ATLAS eHealth country profiles: Based on the findings of the second global survey on eHealth. (Global Observatory for eHealth Series - Volume 1). Geneva. Retrieved from http: //www.who.int/goe.

[4] Schweitzer, J. \& Synowiec, C. 2012. The economics of eHealth and mHealth. Journal of Health Communication, 17 (sup1), pp 73-81. https://doi.org/10.1080/10810730.2011.649158. 
[5] Byrne, C.M., Mercincavage, L.M., Pan, E.C., Vincent, A.G., Johnston, D.S. \& Middleton, B. 2010. The value from investments in health information technology at the U.S. Department of Veterans Affairs. Health Affairs (Project Hope), 29(4), pp 629-38. https://doi.org/10.1377/hlthaff.2010.0119.

[6] Huang, F., Blaschke, S. \& Lucas, H. 2017. Beyond pilotitis: Taking digital health interventions to the national level in China and Uganda. Globalization and Health, 13(1), pp 1-11. https: / /doi.org/10.1186/s12992-017-0275-z.

[7] WHO \& ITU. 2012. National eHealth strategy toolkit. Geneva: WHO.

[8] Boonstra, A. \& Broekhuis, M. 2010. Barriers to the acceptance of electronic medical records by physicians: From systematic review to taxonomy and interventions. BMC Health Services Research, 10(231), pp 1-17. https://doi.org/10.1186/1472-6963-10-231.

[9] Peek, S.T.M., Wouters, E.J.M., van Hoof, J., Luijkx, K.G., Boeije, H R. \& Vrijhoef, H J M. 2014. Factors influencing acceptance of technology for aging in place: A systematic review. International Journal of Medical Informatics, 83(4), pp 235-248. https://doi.org/10.1016/j.ijmedinf.2014.01.004.

[10] Fischer, S.H., David, D., Crotty, B.H., Dierks, M. \& Safran, C. 2014. Acceptance and use of health information technology by community-dwelling elders. International Journal of Medical Informatics, 83(9), pp 624-635. https://doi.org/10.1016/j.ijmedinf.2014.06.005.

[11] Anderson, J.G. 2007. Social, ethical and legal barriers to E-health. International Journal of Medical Informatics, 76(5-6), pp 480-483. https://doi.org/10.1016/j.ijmedinf.2006.09.016.

[12] Quaglio, G., Dario, C., Karapiperis, T., Delponte, L., Mccormack, S., Tomson, G., Micheletti, G., Bonnardot, L., Putoto, G. \& Zanaboni, P. 2016. Information and communications technologies in low and middle-income countries: Survey results on economic development and health. Health Policy and Technology, 5(4), pp 318-329. https://doi.org/10.1016/j.hlpt.2016.07.003.

[13] Luna, D., Almerares, A., Mayan, J.C., González Bernaldo de Quirós, F. \& Otero, C. 2014. Health informatics in developing countries: Going beyond pilot practices to sustainable implementations: A review of the current challenges. Healthcare Informatics Research, 20(1), pp 3-10. https: / /doi.org/10.4258/hir.2014.20.1.3.

[14] Van der Meijden, M.J,. Tange, H.J., Troost, J. \& Hasman, A. 2003. Determinants of success of inpatient clinical information systems: A literature review. Journal of the American Medical Informatics Association, 10(3), pp 235-243. https://doi.org/10.1197/jamia.M1094.

[15] Hadji, B., Martin, G., Dupuis, I., Campoy, E. \& Degoulet, P. 2016. 14 years longitudinal evaluation of clinical information systems acceptance: The HEGP case. International Journal of Medical Informatics, 86 , pp 20-29. https://doi.org/10.1016/j.ijmedinf.2015.11.016.

[16] Tilahun, B. \& Fritz, F. 2015. Comprehensive evaluation of electronic medical record system use and user satisfaction at five low-resource setting hospitals in Ethiopia. JMIR Medical Informatics, 3(2), pp 1-17. https: //doi.org/10.2196/medinform.4106

[17] Michel-Verkerke, M.B., Stegwee, R.A. \& Spil, T.A. 2015. The six P's of the next step in electronic patient records in the Netherlands. Health Policy and Technology, 4(2), pp 137-143. https://doi.org/10.1016/j.hlpt.2015.02.011.

[18] Isabalija, S.R., Mbarika, V. \& Kituyi, G.M. 2013. A framework for sustainable implementation of emedicine in transitioning countries. International Journal of Telemedicine and Applications, pp 615-617. https: / /doi.org/10.1155/2013/615617.

[19] Mettler, T. 2015. Anticipating mismatches of HIT investments: Developing a viability-fit model for e-health services. International Journal of Medical Informatics, 85, pp 104-115. https: //doi.org/10.1016/j.ijmedinf.2015.10.002.

[20] Fritz, F., Tilahun, B. \& Dugas, M. 2015. Success criteria for electronic medical record implementations in low-resource settings: A systematic review. Journal of the American Medical Informatics Association, 22(2), pp 479-488. https://doi.org/10.1093/jamia/ocu038.

[21] Jahangirian, M. \& Taylor, S.J.E. 2015. Profiling e-health projects in Africa: Trends and funding patterns. Information Development, 31(3), pp 199-218. https://doi.org/10.1177/0266666913511478.

[22] Marchewka, J. 2003. Information technology project management - providing measurable organizational value. Danvers: John Wiley \& Sons, Inc.

[23] WHO. 2012. Framework and standards for country health information systems. Geneva: WHO. https: / /doi.org/10.4018/978-1-60566-988-5.

[24] Aqil, A,. Lippeveld, T. \& Hozumi, D. 2009. PRISM framework: A paradigm shift for designing, strengthening and evaluating routine health information systems. Health Policy and Planning, 24(3), pp 217-228. https: / /doi.org/10.1093/heapol/czp010.

[25] Samarthya-Howard, A. 2016. Curing pilot-itis for mHealth. Praekelt.org. Retrieved May 31, 2018 from http://blog.praekeltfoundation.org/post/147639334452/curing-pilot-itis-for-mhealth.

[26] Franz-Vasdeki, J., Pratt, B.A., Newsome, M. \& Germann, S. 2015. Taking mHealth solutions to scale: Enabling environments and successful implementation. Journal of Mobile Technology in Medicine, 4(1), pp 35-38. https://doi.org/10.7309/jmtm.4.1.8.

[27] Fiksel, J. 2003. Designing resilient, sustainable systems. Environmental Science \& Technology, 37(23), pp 5330-5339. Retrieved from http://www.ncbi.nlm.nih.gov/pubmed/14700317.

[28] Buys, L., Mengersen, K., Johnson, S., van Buuren, N. \& Chauvin, A. 2014. Creating a sustainability scorecard as a predictive tool for measuring the complex social, economic and environmental impacts of industries, a case study: Assessing the viability and sustainability of the dairy industry. Journal of Environmental Management, 133, pp 184-192. Retrieved from www.elsevier.com/locate/jenvman. 
[29] Zeidan, R., Boechat, C. \& Fleury, A. 2014. Developing a sustainability credit score system. Journal of Business Ethics, 127(2), pp 283-296. https://doi.org/10.1007/s10551-013-2034-2.

[30] Hay, L., Duffy, A. \& Whitfield, R.I. 2014. The sustainability cycle and loop: Models for a more unified understanding of sustainability. Journal of Environmental Management, 133 (2014), pp 232-257.

[31] Musango, J.K. \& Brent, A.C. 2010. A conceptual framework for energy technology sustainability assessment. Energy for Sustainable Development, 15(1), pp 84-91. https://doi.org/10.1016/j.esd.2010.10.005.

[32] Parv, L., Saluse, J., Aaviksoo, A., Tiik, M., Sepper, R. \& Ross, P. 2012. Economic impact of a nationwide interoperable e-Health system using the PENG evaluation tool. Studies in Health Technology and Informatics, 180, pp 876-80. Retrieved from http://www.ncbi.nlm.nih.gov/pubmed/22874318.

[33] Rippen, H.E., Pan, E.C., Russell, C., Byrne, C.M. \& Swift, E.K. 2013. Organizational framework for health information technology. International Journal of Medical Informatics, 82(4), pp e1-e13.

[34] De Rosis, S. \& Nuti, S. 2018. Public strategies for improving eHealth integration and long-term sustainability in public health care systems: Findings from an Italian case study. The International Journal of Health Planning and Management, 33(1), pp e131-e152. https://doi.org/10.1002/hpm.2443.

[35] Fanta, G.B., Pretorius, L. \& Erasmus, L. 2018. Economic analysis of sustainable ehealth implementation in developing countries: A systematic review. International Association for Management of Technology. Birmingham, UK, pp 1-16.

[36] Baxter, G. \& Sommerville, I. 2011. Socio-technical systems: From design methods to systems engineering. Interacting with Computers, 23(1), pp 4-17. https://doi.org/10.1016/j.intcom.2010.07.003.

[37] Harrison, M.I., Koppel, R. \& Bar-Lev, S. 2007. Unintended consequences of information technologies in health care - An interactive sociotechnical analysis. Journal of the American Medical Informatics Association, 14(5), pp 542-9. https://doi.org/10.1197/jamia.M2384.

[38] Snowden, D.J.D. \& Boone, M.M.E. 2007. A leader's framework for decision making. Harvard Business Review, 85(11), pp 68-76.

[39] Sterman, J.D. 2000. Business dynamics: System thinking and modeling for a complex world. New York: McGraw-Hill.

[40] Carayon, P. 2006. Human factors of complex sociotechnical systems. Applied Ergonomics, 37(4 SPEC. ISS.), pp 525-535. https://doi.org/10.1016/j.apergo.2006.04.011.

[41] Cresswell, K. \& Sheikh, A. 2012. Organizational issues in the implementation and adoption of health information technology innovations: An interpretative review. International Journal of Medical Informatics, 82(5), pp e73-e86. https://doi.org/10.1016/j.ijmedinf.2012.10.007.

[42] Khoja, S., Durrani, H., Scott, R.E., Sajwani, A. \& Piryani, U. 2013. Conceptual framework for development of comprehensive e-health evaluation tool. Telemedicine Journal and e-Health: The official journal of the American Telemedicine Association, 19(1), pp 48-53.

[43] Leon, N., Schneider, H. \& Daviaud, E. 2012. Applying a framework for assessing the health system challenges to scaling up mHealth in South Africa. BMC Medical Informatics and Decision Making, 12(123), pp 123. https: //doi.org/10.1186/1472-6947-12-123.

[44] Lluch, M. 2011. Healthcare professionals' organisational barriers to health information technologies - a literature review. International Journal of Medical Informatics, 80(12), pp $849-62$. https: / /doi.org/10.1016/j.ijmedinf.2011.09.005.

[45] Gorla, N., Somers, T.M. \& Wong, B. 2010. Organizational impact of system quality, information quality, and service quality. Journal of Strategic Information Systems, 19(3), pp $207-228$. https://doi.org/10.1016/j.jsis.2010.05.001.

[46] DeLone, W.H. \& McLean, E.R. 2003. The DeLone and McLean model of information systems success: A tenyear update. Journal of Management Information Systems, 19(4), pp 9-30. https://doi.org/10.1073/pnas.0914199107.

[47] Al-Mamary, Y.H., Shamsuddin, A. \& Aziati, N. 2014. Factors affecting successful adoption of management information systems in organizations towards enhancing organizational performance. American Journal of Systems and Software, 2(5), pp 121-126. https://doi.org/10.12691/ajss-2-5-2.

[48] Davis, F.D. 1989. Perceived usefulness, perceived ease of use, and user acceptance of information technology. MIS Quarterly, 13(3), pp 319-340.

[49] Venkatesh, V. \& Bala, H. 2008. Technology acceptance model 3 and a research agenda on interventions. Decision Sciences, 39(2), pp 273-315. https://doi.org/10.1111/j.1540-5915.2008.00192.x.

[50] Petter, S., DeLone, W. \& McLean, E.R. 2013. Information systems success: The quest for the independent variables. Journal of Management Information Systems, 29(4), pp 7-62.

[51] Aarts, J., Peel, V. \& Wright, G. 1998. Organizational issues in health informatics: A model approach. International Journal of Medical Informatics, 52(1-3), pp 235-242. https://doi.org/10.1016/S13865056(98)00142-7.

[52] Cresswell, K., Majeed, A., Bates, D.W. \& Sheikh, A. 2012. Computerised decision support systems for healthcare professionals: An interpretative review. Informatics in Primary Care, 20(2), pp 115-128.

[53] Bilbao-Osorio, B., Dutta, S. \& Lanvin, B. 2014. The global information technology report 2014: Rewards and risks of big data. Geneva: World Economic Forum. Retrieved from http://www3.weforum.org/docs/WEF_GloballnformationTechnology_Report_2014.pdf.

[54] Khoja, S., Scott, R.E., Casebeer, A.L., Mohsin, M., Ishaq, A.F. \& Gilani, S. 2007. e-Health readiness assessment tools for healthcare institutions in developing countries. Telemedicine Journal and e-Health, 13(4), pp 425-431. https://doi.org/10.1089/tmj.2006.0064. 
[55] Jones, T., Stroetmann, K., Dobrev, A. \& Stroetmann, V. 2011. eHealth for African countries - sustainable strategies. In IST-Africa 2011, 1-11.

[56] De la Torre-Diez, I., Lopez-Coronado, M., Vaca, C., Aguado, J.S. \& de Castro, C. 2015. Cost-utility and cost-effectiveness studies of telemedicine, electronic, and mobile health systems in the literature: A systematic review. Telemedicine Journal and e-Health: The official journal of the American Telemedicine Association, 21(2), pp 81-85. https://doi.org/10.1089/tmj.2014.0053.

[57] Stroetmann, V., Motti, D. \& Kalra, D. 2015. Adoption of interoperable EHRs: Barriers, challenges, incentives. Gent: European Institute for Innovation through Health Data. Retrieved from http: / / www.semantichealthnet.eu/SemanticHealthNet/assets/File/SHN\%20288408\%20D3_3\%20rev2\%20An nex\%2013_Stroetman_SHN_D3_3_final.pdf.

[58] Project Management Institute. 2013. A guide to the project management body of knowledge (PMBOK). Newtown Square, Pennsylvania: PMI. https://doi.org/10.1002/pmj.20125.

[59] Van Dyk, L., Wentzel, M.J., van Limburg, A.H.M., van Gemert-Pijnen, J.E.W.C. \& Schutte, C.S.L. 2012. Business models for sustained eHealth implementation: Lessons from two continents. Proceedings of the 42th International Conference for Computers and Industrial Engineering, 234(July), pp 1-16.

[60] Belay, H., Azim, T. \& Kassahun, H. 2013. Assessment of health management information system (HMIS) performance in SNNPR, Ethiopia. Hawassa, Ethiopia: SNNP Regional Health Bureau.

[61] Chen, Y. 2011. Understanding technology adoption through system dynamics approach: A case study of RFID technology. 2011 IFIP 9th International Conference on Embedded and Ubiquitous Computing, pp 366371. https: //doi.org/10.1109/EUC.2011.75.

[62] Mutingi, M. \& Matope, S. 2013. Dynamics of information technology adoption in a complex environment. 2013 IEEE International Conference on Industrial Technology (ICIT), pp 1466-1471. https: //doi.org/10.1109/ICIT.2013.6505888.

[63] Elbert, N.J., van Os-Medendorp, H., van Renselaar, W., Ekeland, A.G., Hakkaart-van Roijen, L., Raat, H., Nijsten, T.E.C. \& Pasmans, S.G.M.A. 2014. Effectiveness and cost-effectiveness of eHealth interventions in somatic diseases: A systematic review of systematic reviews and meta-analyses. Journal of Medical Internet Research, 16(4), pp 1-27. https://doi.org/10.2196/jmir.2790.

[64] FMOH. 2015. HSTP - Health sector transformation plan. Addis Ababa, Ethiopia: FMOH. 